\title{
The influence of texture on the reversible elastocaloric effect of a polycrystalline $\mathrm{Ni}_{50} \mathrm{Mn}_{32} \mathrm{In}_{16} \mathrm{Cr}_{2}$ alloy
}

Fernando Hernández-Navarro, Juan-Pablo Camarillo-Garcia, Christian-Omar Aguilar-Ortiz, Horacio FloresZúñiga, David Ríos, José-Gonzalo González, and Pablo Álvarez-Alonso

Citation: Appl. Phys. Lett. 112, 164101 (2018); doi: 10.1063/1.5018732

View online: https://doi.org/10.1063/1.5018732

View Table of Contents: http://aip.scitation.org/toc/apl/112/16

Published by the American Institute of Physics

\section{Articles you may be interested in}

Giant elastocaloric effect and its irreversibility in [001]-oriented $\mathrm{Ni}_{45} \mathrm{Mn}_{36.5} \mathrm{In}_{13.5} \mathrm{Co}_{5}$ meta-magnetic shape memory alloys

Applied Physics Letters 110, 021906 (2017); 10.1063/1.4973965

The mechanism of $\Delta \mathrm{T}$ variation in coupled heat transfer and phase transformation for elastocaloric materials and its application in materials characterization

Applied Physics Letters 111, 223902 (2017); 10.1063/1.5001971

Orientation dependent cyclic stability of the elastocaloric effect in textured Ni-Mn-Ga alloys

AIP Advances 8, 055312 (2018); 10.1063/1.5028212

Elastocaloric effect in a textured polycrystalline Ni-Mn-In-Co metamagnetic shape memory alloy Applied Physics Letters 105, 161905 (2014); 10.1063/1.4899147

Barocaloric and magnetocaloric effects in $(\mathrm{MnNiSi})_{1-\mathrm{X}}(\mathrm{FeCoGe})_{\mathrm{X}}$

Applied Physics Letters 112, 021907 (2018); 10.1063/1.5011743

Elastocaloric effects in ultra-fine grained NiTi microwires processed by cold-drawing APL Materials 6, 036102 (2018); 10.1063/1.5021631

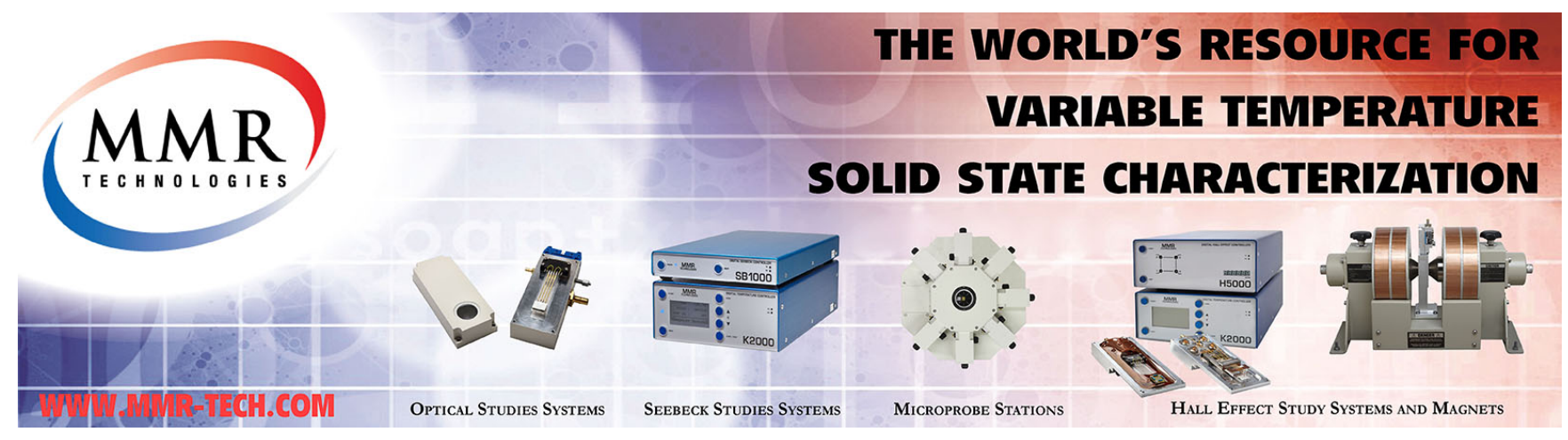




\title{
The influence of texture on the reversible elastocaloric effect of a polycrystalline $\mathrm{Ni}_{50} \mathrm{Mn}_{32} \mathrm{In}_{16} \mathrm{Cr}_{2}$ alloy
}

\author{
Fernando Hernández-Navarro, ${ }^{1}$ Juan-Pablo Camarillo-Garcia, ${ }^{1, a)}$ \\ Christian-Omar Aguilar-Ortiz, ${ }^{1}$ Horacio Flores-Zúñiga, ${ }^{1}$ David Ríos, ${ }^{1}$ \\ José-Gonzalo González, ${ }^{2}$ and Pablo Álvarez-Alonso ${ }^{3}$ \\ ${ }^{1}$ Instituto Potosino de Investigación Científica y Tecnológica, Camino a la Presa San José 2055, \\ Col. Lomas 4a, CP. 78216 San Luis Potosí, Mexico \\ ${ }^{2}$ Instituto de Investigaciones en Materiales, Universidad Nacional Autónoma de México, Circuito Exterior s/n, \\ Ciudad Universitaria, Coyoacán, CP. 04510 Ciudad de México, Mexico \\ ${ }^{3}$ Universidad de Oviedo Campus de Llamaquique, Calvo Sotelo s/n, CP. 33005 Oviedo, Spain
}

(Received 8 December 2017; accepted 3 April 2018; published online 16 April 2018; corrected 9 May 2018)

\begin{abstract}
We have studied the correlation between the elastocaloric effect and the crystallographic direction where a uniaxial stress is applied in a textured polycrystalline Ni-Mn-In-Cr ferromagnetic shape memory alloy; this alloy displays martensitic transformation around room temperature and presents an $\mathrm{L} 2_{1}$ cubic structure in the austenite phase. The texture in the material was induced by simple arc melting synthesis; using inverse pole figures, a favored grain growth was shown in the direction [001] perpendicular to the cooled surface. The elastocaloric effect was determined by direct measurements of the adiabatic temperature change $\left(\Delta T_{\mathrm{ad}}{ }^{\mathrm{me}}\right)$, while compressive stress was applied and released; hereby, it has been shown that it is possible to exploit the columnar growth texture in order to obtain a large and reversible elastocaloric effect. The reversible elastocaloric response was measured between 280 and $310 \mathrm{~K}$ by applying moderate stresses of 50,75 , and $100 \mathrm{MPa}$ in the [001], [111], and [011] directions. A strong interrelation was found in the cyclic $\Delta T_{\mathrm{ad}}{ }^{\mathrm{me}}$ values of $-3.9,-2.0$, and $-1.3 \mathrm{~K}$ after unloading a compressive stress of $100 \mathrm{MPa}$ applied mainly in the [001], [111], and [011] directions, respectively. Published by AIP Publishing.

https://doi.org/10.1063/1.5018732
\end{abstract}

A caloric effect refers to the thermal response (isothermal entropy change, $\Delta \mathrm{S}_{\text {iso }}$, or adiabatic temperature change, $\Delta T_{\text {ad }}$ ) of a material when it is subjected to external stimuli. This response can be larger in the vicinity of a structural phase transition. ${ }^{1}$ Caloric materials can be classified as magnetocaloric when the caloric response is due to an external magnetic field, electrocaloric if the response is due to an electric field, mechanocaloric when the response is due to hydrostatic pressure (barocaloric effect) or uniaxial stress (elastocaloric effect), and multicaloric if the material shows more than one type of caloric effect. ${ }^{2}$ During the past few years, solid-state refrigeration has become a fast-growing research field. Environmentally friendly and potentially high efficient cooling technologies might replace the common compression-vapor refrigeration cycle. So far, efforts have been focused around the magnetocaloric effect; ${ }^{3-5}$ nevertheless, the elastocaloric effect has been highlighted as one of the most promising among refrigeration technologies ${ }^{6}$ thanks to the large values of $\Delta T_{\text {ad }}$ in a wide working temperature span obtained at lower costs than in magnetic systems. ${ }^{7}$ Recent work has pointed out the relevance of the development of multicaloric materials in order to improve the range and response for their applications. It stimulates the research related to solid-state refrigeration in order to approach this technology in development to reality in the near future. ${ }^{1,8}$

The caloric effect reports, including the elastocaloric effect, are broadly based in $\Delta \mathrm{S}_{\text {iso }}$, calculated via a Maxwell

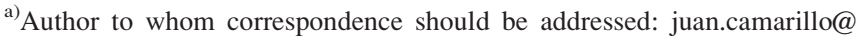
ipicyt.edu.mx and jp.camarillo.garcia@gmail.com
}

relation (indirect method); the highest values were reported for TiNi alloys; ${ }^{2}$ nevertheless, a large applied stress is often needed, and also, large $\Delta S_{\text {iso }}$ has been recently shown in Heusler alloys. ${ }^{9,10}$ Direct $\Delta T_{\text {ad }}$ measurements are often the most straightforward method to evaluate the elastocaloric effect, and a comparison between different alloys was presented in Ref. 11. Both $\Delta \mathrm{S}_{\text {iso }}$ and $\Delta T_{\text {ad }}$ are related to $\Delta H$ and $\Delta S_{\text {transformation, which limits the maximum response due to an }}$ external stimuli; latent heat in TiNi alloys can be as large as $30 \mathrm{~J} \mathrm{~g}^{-1}$, and meanwhile, in ferromagnetic alloys, it is up to $10 \mathrm{~J} \mathrm{~g} \mathrm{~g}^{-1} \cdot{ }^{12}$ With this in mind, extensive studies that correlate the latent heat (and transformation entropy) with the transformation temperatures are of deep interest. ${ }^{13,14}$

The application of an external field, named the magnetic field or the mechanical field (hydrostatic pressure or uniaxial stress), to ferromagnetic shape memory alloys produces a modification of the equilibrium conditions in the material, giving thermodynamic stability to one phase over the other. This is the case for the metamagnetism in Ni-Mn-In-Co ${ }^{15,16}$ or Ni-Mn-Sn-Co ${ }^{17}$ alloys, where the austenite phase can be induced by the application of a magnetic field well below the zero field austenite start temperature $\left(\mathrm{A}_{\mathrm{s}}^{\mathrm{H}=0}\right)$. Conversely, the martensite can be favored over the austenite by applying a mechanical field to those alloys that present conventional baro- or elastocaloric effects. ${ }^{18-20}$ As the phase favored by the application of uniaxial stress is the martensite and this is highly anisotropic, in the elastocaloric effect, it is relevant to correlate the applying stress direction with the crystalline direction in the material. This is relatively simple in single crystal materials; for instance, in Ni-Fe-Ga single crystals, 
the adiabatic temperature change due to releasing an external stress of $\Delta \sigma=300 \mathrm{MPa}$ was compared for the [001] and [111] directions, displaying quite different values of $10.2 \mathrm{~K}$ and $3.2 \mathrm{~K}$, respectively. ${ }^{21}$ Nevertheless, a highly textured material can offer a good approximation, avoiding the complexity of single crystal growth or a highly specific orientation process. In recent reports, the elastocaloric effect response as a function of the crystallographic direction in a mechanocaloric material has been highlighted in Ni-Mn-InCo alloys; ${ }^{22,23}$ nonetheless, a specialized process to promote texture was necessary.

In this paper, we report the mechanical adiabatic temperature change $\left(\Delta T_{\mathrm{ad}}{ }^{\mathrm{me}}\right)$ near the martensitic transformation (MT) of a textured arc-melted $\mathrm{Ni}_{50} \mathrm{Mn}_{32} \mathrm{In}_{16} \mathrm{Cr}_{2}$ alloy due to the release of a uniaxial compressive stress of up to $100 \mathrm{MPa}$. The alloy exhibits a $\Delta T_{\mathrm{ad}}{ }^{\mathrm{me}}$ of $-3.9,-2.0$, and $-1.3 \mathrm{~K} \pm 0.1 \mathrm{~K}$ after releasing the applied stress close to the [001], [111], and [011] directions of the austenite phase, respectively.

The polycrystalline ingot of work was prepared by arcmelting from pure metals ( $>99.9 \%)$ under an argon atmosphere on a water-cooled $\mathrm{Cu}$ crucible. The bulk was re-melted several times and annealed at $1173 \mathrm{~K}$ for $24 \mathrm{~h}$ to ensure homogeneity and then quenched into a mixture of ice-water. The exploited texture in the sample was induced only by arc melting cooled surface synthesis; it is well known that it produces a columnar grain growth in the normal direction to the surface.

The nominal $\mathrm{Ni}_{50} \mathrm{Mn}_{32} \mathrm{In}_{16} \mathrm{Cr}_{2}$ presents an average composition determined by EDS of $\mathrm{Ni}_{50.1 \pm 1.0} \mathrm{Mn}_{32.0 \pm 1.0} \mathrm{In}_{15.4 \pm 0.2}$ $\mathrm{Cr}_{2.5 \pm 0.2}$. Using a low speed diamond saw, three pieces were cut from the ingot and prepared as parallelepipeds with cross-sections of $6.20,5.41$, and $4.43 \mathrm{~mm}^{2}$, lengths of 4.07 , 3.48 , and $2.77 \mathrm{~mm}$, and masses of $0.2054,0.1534$, and $0.1002 \mathrm{~g}$, for samples called 1,2 , and 3 , respectively. The cross-section of the sample where the stress was applied was perpendicular to the growth direction in sample 1 and parallel in samples 2 and 3. The crystal texture was determined with an X-Ray diffractometer, model Rigaku Ultima IV equipped with cross beam optics (CBO) and wavelength $\mathrm{Cu}-$ $\mathrm{K} \alpha$. Inverse pole figures (IPF) were calculated using MTEX (Matlab Toolbox). ${ }^{24}$ The samples undergo martensitic transformation (MT) between $295 \mathrm{~K}$ and $279 \mathrm{~K}\left(\mathrm{~A}_{\mathrm{F}}\right.$ and $\mathrm{M}_{\mathrm{F}}$, respectively). The DSC curves presented in Fig. 1 were obtained using a commercial TA-instrument calorimeter

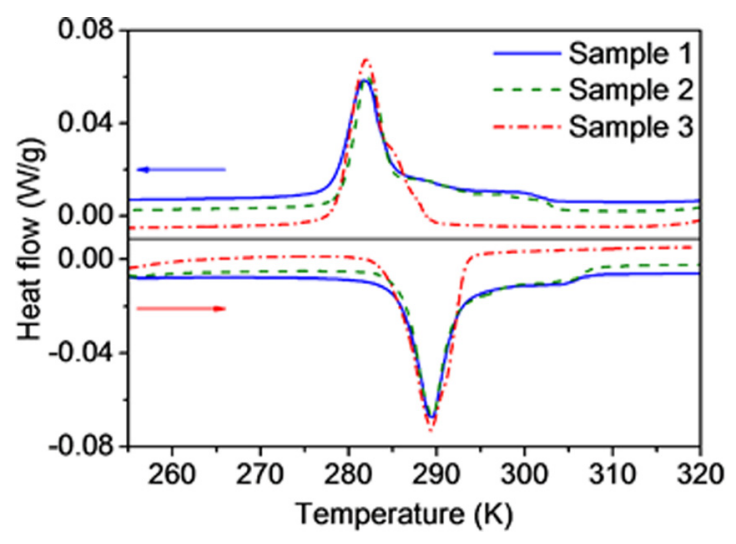

FIG. 1. Thermograms of the $\mathrm{Ni}_{50} \mathrm{Mn}_{32} \mathrm{In}_{16} \mathrm{Cr}_{2}$ alloy samples.
TA-Q200. Room temperature X-Ray diffraction (XRD) patterns (Fig. 2) were collected using a Rigaku SmartLab X-ray diffractometer over the corresponding cross-section of each sample and in a powdered sample.

The adiabatic temperature change in the $\mathrm{Ni}_{50} \mathrm{Mn}_{32} \mathrm{In}_{16} \mathrm{Cr}_{2}$ samples was determined using purpose-built equipment fully described in Ref. 25. In the measurement of the adiabatic temperature change, a $0.13 \mathrm{~mm}$ diameter K-type thermocouple attached to the middle of the sample was employed, with a sampling frequency of $4 \mathrm{~Hz}$, while uniaxial stress is manually applied or released.

The average transformation enthalpy and entropy were quantified from the DSC curves shown in Fig. 1 as 11.0 $\pm 0.6 \mathrm{~J} \mathrm{~g}^{-1}$ and $39.0 \pm 2.4 \mathrm{~J} \mathrm{~K}^{-1} \mathrm{~kg}^{-1}$, respectively. It can be seen that the martensitic transformation occurs around room temperature, and the small differences in the transition path between samples are caused by unavoidable small composition differences, impurities, etc. ${ }^{26}$ Nevertheless, a good agreement in these curves is observed for the three studied samples.

Figure 2 shows the XRD patterns of samples 1,2, and 3, as compared with those from powder and theoretical ones. The powder sample [Fig. 2(d)] presents a good agreement with the theoretical XRD pattern of a cubic L2 $2_{1}$ austenite structure at $295 \mathrm{~K}$ with space group 225 [Fig. 2(e)]. From this, a lattice parameter of $0.600(5) \mathrm{nm}$ was determined.

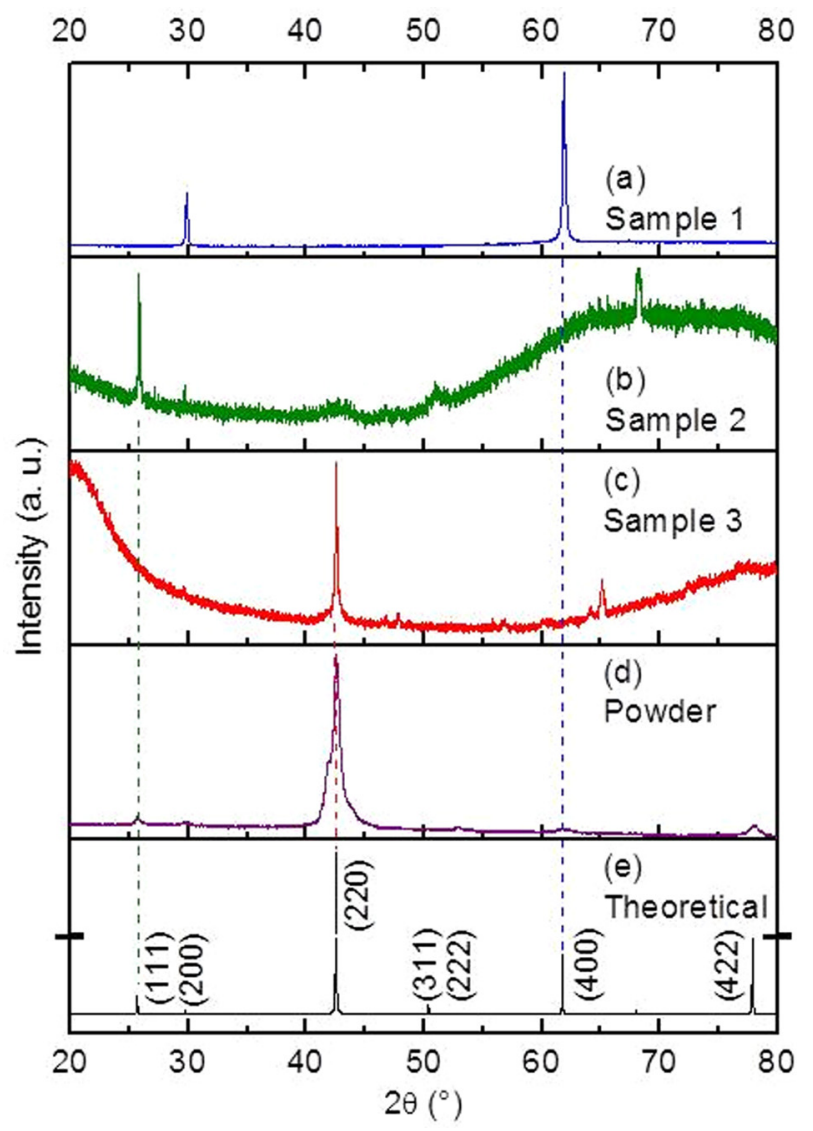

FIG. 2. X-ray diffraction patterns (a)-(c) of the bulk samples measured on the surface of applied stress. (d) XRD pattern of the powdered sample and (e) theoretical pattern for the cubic $\mathrm{L}_{1}$ structure with $\mathrm{Ni}_{50} \mathrm{Mn}_{32} \mathrm{In}_{16} \mathrm{Cr}_{2}$ stoichiometry. It is important to note the break in the y axis at the theoretical pattern, whose function is to help to visualize smaller diffraction peaks. 
Sample 1, with its cross-section perpendicular to the growth direction, shows (400) as the favored diffracted plane [Fig. 2(a)]. The samples with cross-sections parallel to the growth direction present main diffraction peaks in the (111) and (220) planes [Figs. 2(b) and 2(c), respectively]. These results show that the (400) planes are stacked perpendicular to the direction of the columnar growth. This kind of texture has been also reported in $\mathrm{Mn}-\mathrm{Ni}$-In ribbons with an undercooled surface. $^{27}$

The texture characterization was analyzed by the examination of inverse pole figures (IPF) over sample 3 schematized in Fig. 3(a), where the sample is located in the origin of the $\mathrm{x}, \mathrm{y}$, and $\mathrm{z}$ axes and the length of the sample is parallel to the $\mathrm{z}$ axis. The IPF taken in the $\mathrm{x}$-axis of sample 3 corresponds to a parallel direction to the one where the elastocaloric effect has been measured in sample 1 [Fig. 3(b)] and analogously occurs with the y-axis of sample 3 and the direction of the measurement of the elastocaloric effect in sample 2 [Fig. 3(c)]. It can be seen in Fig. 3(d) that in the z-axis (parallel to the applied stress direction), the sample presents texture on the [011] crystallographic direction.

By analyzing these results, XRD and IPF support the proposal to obtain textured materials from arc melting. It can be seen that the [011] texture observed in the IPF [Fig. 3(d)] is in good agreement with the preferential (220) planes presented in the XRD pattern of Fig. 2(c) for sample 3. The same occurs with sample 1 where the diffracted planes in XRD presented in Fig. 2(a) are (200) and (400), and the texture determined by IPF in Fig. 3(b) shows [001]. Sample 2 exhibits agreement as well between the XRD (111) diffracted planes and the IPF [111] texture presented in Figs. 2(b) and 3 (c), respectively.

Some considerations should be taken in order to reduce the error in direct measurements of $\Delta T_{\mathrm{ad}}$ me . In our setup, the loading/unloading process was done manually in one step, and the sample was thermally insulated using fiberglass to diminish the heat interchange with the surroundings. A polymer with low thermal conductivity is located between the compressive stem and the sample. The sample holder, on the other hand, tends to lead the sample temperature to the measurement temperature, which can result in a lower $\Delta T_{\mathrm{ad}}$ me than those actually displayed by the sample. Recently, the inhomogeneity of $\Delta T_{\mathrm{ad}}{ }^{\text {me }}$ over the sample due to a partial induction of the martensite has been pointed out as inconvenient in the determination of the average adiabatic temperature change via a thermocouple. Nevertheless, in order to improve the measurement using thermocouples to ensure good thermal contact with the sample, a small mass sensor and high sampling frequency are recommended. ${ }^{28}$ It should be mentioned that our measurements were taken using a single thermocouple, and therefore, it is not possible to describe an adiabatic temperature change gradient along the sample. However, it is expected to be small due to the thermocouple placement and size of the sample. The cyclic adiabatic temperature change was measured while applying and releasing stresses of 50, 75, and $100 \mathrm{MPa}$ near to the [001], [011], and [111] crystallographic directions of the austenite phase. An example of these measurements is shown in Fig. 4(a) for the alloy compressed along the [001] direction as a function of time at $297 \mathrm{~K}$. From times 0 to 1 , the sample stabilizes its temperature $\left(T_{0}\right)$; at time 1 , the compressive stress is applied, and the maximum adiabatic temperature change is obtained at time 2. From times 3 to 4 , the stress remains applied to the sample whilst it thermalizes, and suddenly, the sample is unloaded at time 4 , and its temperature changes adiabatically to the minimum value at time 5, and the cycle is repeated. The resulting $\Delta T_{\mathrm{ad}}{ }^{\mathrm{me}}$ values as a function of applied stress, $\Delta \sigma$, and measured temperature, $\mathrm{T}_{0}$, are presented in Figs. 4(b)-4(d). With the maximum applied stress of $100 \mathrm{MPa}$ in the [001] direction, the temperature of the sample changes as +4.8 and $-3.9 \mathrm{~K}$ for loading and unloading the stress, respectively. In contrast, the samples compressed in [111] and [011] directions change as +2.0 and $-2.0 \mathrm{~K}$ and +1.3 and $-1.3 \mathrm{~K}$ for loading and unloading the stress, respectively. The peak of $\Delta T_{\mathrm{ad}}{ }^{\mathrm{me}}$ is displayed at a higher value of $\mathrm{T}_{0}$ with increasing compressive stress, indicating a shift of the MT to higher temperatures; this has been observed in other magnetic shape memory alloys. ${ }^{10,21}$ As the phase induced by the applied stress is the martensite, and this is highly anisotropic, it is expected to find differences in $\Delta T_{\mathrm{ad}}{ }^{\text {me }}$ with different directions of the applied stress.

A comparison of the dependence of the adiabatic temperature change with the direction of applied stress on ferromagnetic shape memory alloys was made only for singlecrystals ${ }^{21}$ but not on textured polycrystals. It can be seen that there is a clear relationship between $\Delta T_{\mathrm{ad}}{ }^{\text {me }}$ and the direction in which the stress is applied. The response in the [001] direction continue to grow for $T_{0}>A_{F}(295 K)$, in contrast with [111] where the elastocaloric response starts to decrease or [011] where practically vanished. The theoretical maximum value is non-dependent of the direction of application of stress (a)

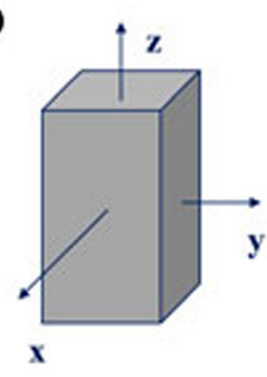

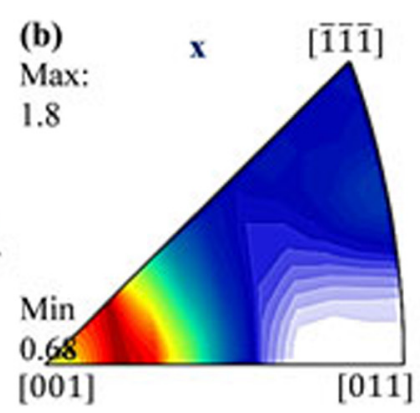

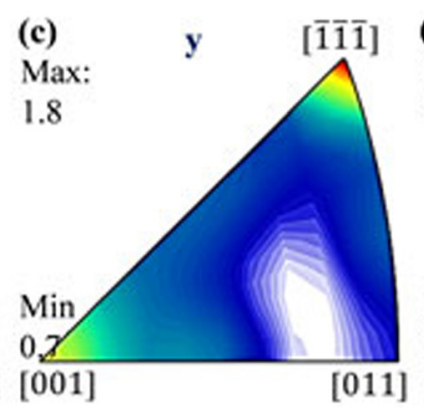

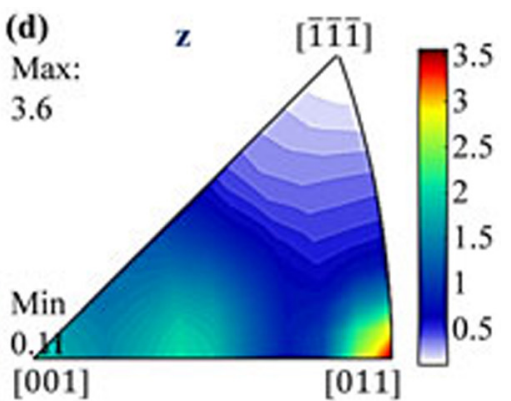

FIG. 3. (a) Measured sample scheme to determine the inverse pole figures. The stress was applied on the surface xy, and thus, the $\mathrm{z}$ axis and the compression stress direction are parallel. (b) IPF obtained on the $\mathrm{x}$-axis of sample 3 of $\mathrm{Ni}_{50} \mathrm{Mn}_{32} \mathrm{In}_{16} \mathrm{Cr}_{2}$. (c) IPF obtained on the $y$-axis of sample 3 and (d) IPF obtained on the $\mathrm{z}$ axis of sample 3 . 

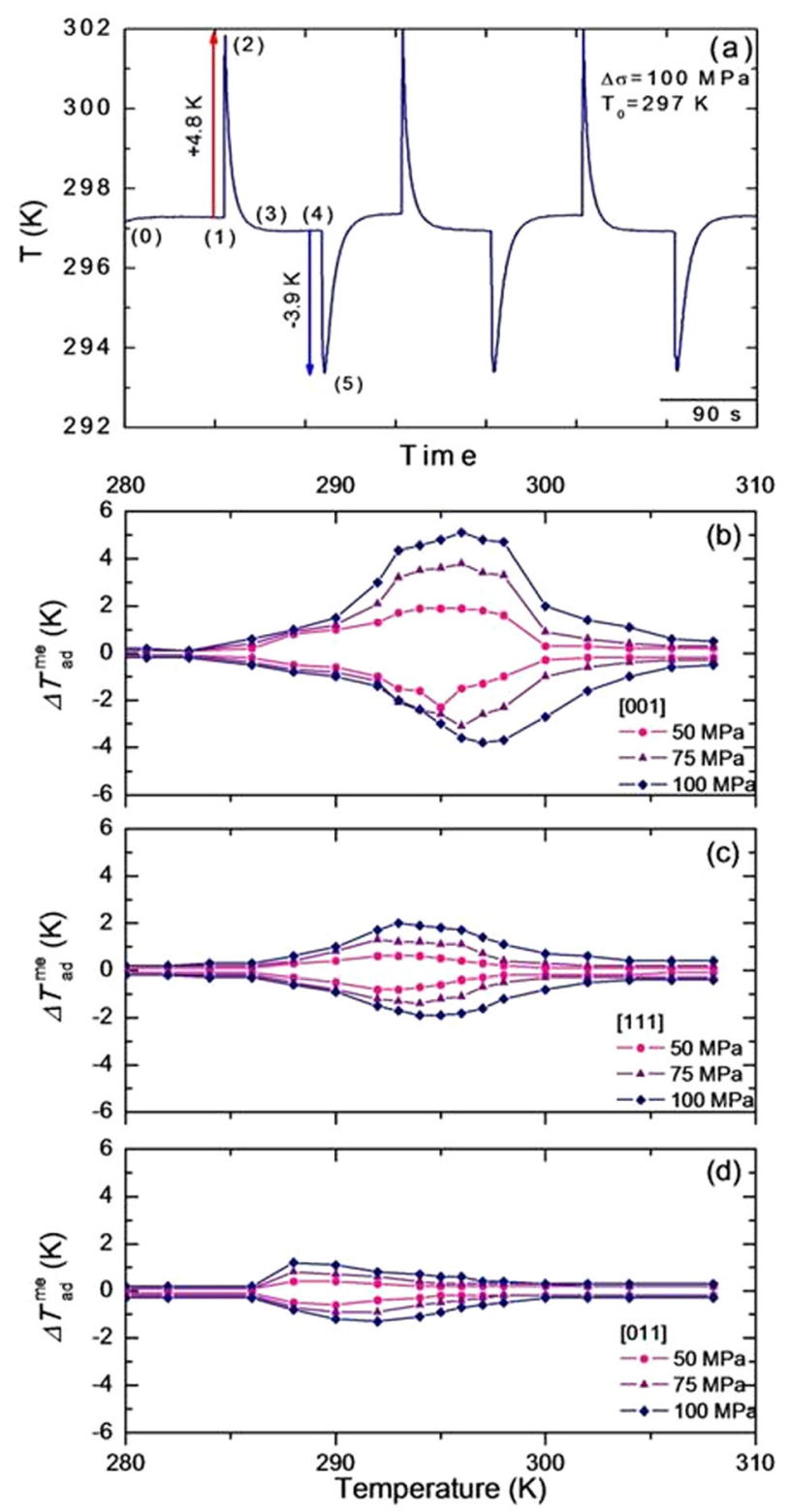

FIG. 4. (a) Description of the cyclic $\Delta T_{\mathrm{ad}}{ }^{\text {me }}$ measurement as a function of time for loading (positive) and unloading (negative) a $100 \mathrm{MPa}$ stress in the [001] direction at $297 \mathrm{~K}$ for the $\mathrm{Ni}_{50} \mathrm{Mn}_{32} \mathrm{In}_{16} \mathrm{Cr}_{2}$ polycrystalline alloy. The adiabatic temperature change as a function of the temperature of the measurement $\left(\mathrm{T}_{0}\right)$ and of the applied stress $(\Delta \sigma)$ in the [001] (b), [111] (c), and [011] (d) directions is shown. Continuous lines are used as a guide for the eyes.

since the transformation entropy change and the specific heat are the same. Then, the difference of the top value between the measured directions should be related to the proportion of the martensitic phase driven by the applied stress. This conclusion is perfectly compatible with the mechanism of formation of martensite in these alloys since the martensitic transformation starts by a first shear in the compact planes of the $L 2_{1}$ structure, i.e., the $\{110\}$ planes, for which the larger Schmid factor of the applied stress is obtained for the [001] direction, followed by [111] and finally by [110] directions. By comparing the top value of $\Delta T_{\mathrm{ad}}$ me it is noticeable that applying stress in the [001] direction of the parent phase can easily induce martensite compared with [111] or [011]. In order to get a more accurate proof of this, stress-strain curves were obtained with an universal test machine Shimadzu AG-1
$100 \mathrm{kN}$ at $293 \mathrm{~K}$. Tests were performed in a different ingot with $\mathrm{As}=289 \mathrm{~K}$ and $\mathrm{Af}=298 \mathrm{~K}$, and then, it is expected a large irreversibility after the first load at $293 \mathrm{~K}$. Figure 5 shows that from fully austenite, the critical stress to start to induce martensite in [001] can be as low as $20 \mathrm{MPa}$, whilst for [110], it increases to $60 \mathrm{MPa}$. The large non-recovery strain between the first and the second load can be related to the amount of martensite induced by stress during the first cycle. Then, applying the stress in [001] induces a larger amount of martensite compared with [110]. Besides, it can be seen that the adiabatic temperature change displayed in the directions [111] and [011] presents a similar value during loading and unloading; the same behavior is presented in the direction [001] but only up to $50 \mathrm{MPa}$. The slight discrepancy between $\Delta T_{\mathrm{ad}}$ loading and $\Delta T_{\mathrm{ad}}$ unloading exhibited in [001] for applied stress over $50 \mathrm{MPa}$ may be attributed to intrinsic dissipative heat of internal friction, which causes an entropy generation, increasing $\Delta T_{\mathrm{ad}}$ loading but decreasing $\Delta T_{\mathrm{ad}}$ unloading . It considers a complete transformation into heat of the dissipative energy due to the hysteresis. ${ }^{23,29-31}$ Then, it suggests that the heat generated by internal friction has a minor influence in $\Delta T_{\mathrm{ad}}{ }^{\text {me }}$ when only a small amount of martensite is induced by stress. By comparing the value of $\Delta T_{\mathrm{ad}}{ }^{\text {me }}$, the main contribution is due to the relationship between the crystallographic direction and the applied stress direction; nevertheless, differences into the grain size between the samples have not been considered. It is expected that the sample with texture in (400) possesses the largest grains and the least amount of grain boundaries in the applied stress direction due to the columnar growth induced by the arc melting process.

A figure of merit proposed for the comparison of the elastocaloric response between materials is the strength of the elastocaloric effect $\left(\left|\Delta T_{\mathrm{ad}}{ }^{\mathrm{me}}\right| /|\Delta \sigma|\right)$; in the $\mathrm{Ni}_{50} \mathrm{Mn}_{32} \mathrm{In}_{16} \mathrm{Cr}_{2}$ samples, during the unloading, this criterion reaches values of 39,20 , and $13 \mathrm{k} \mathrm{GPa}^{-1}$ in the [001], [111], and [011] directions, respectively. Values near to $20 \mathrm{k} \mathrm{GPa}^{-1}$ are comparable with those presented by $\mathrm{Ni}_{48.9} \mathrm{Ti}_{51.1} \cdot{ }^{30}$ The strength of the

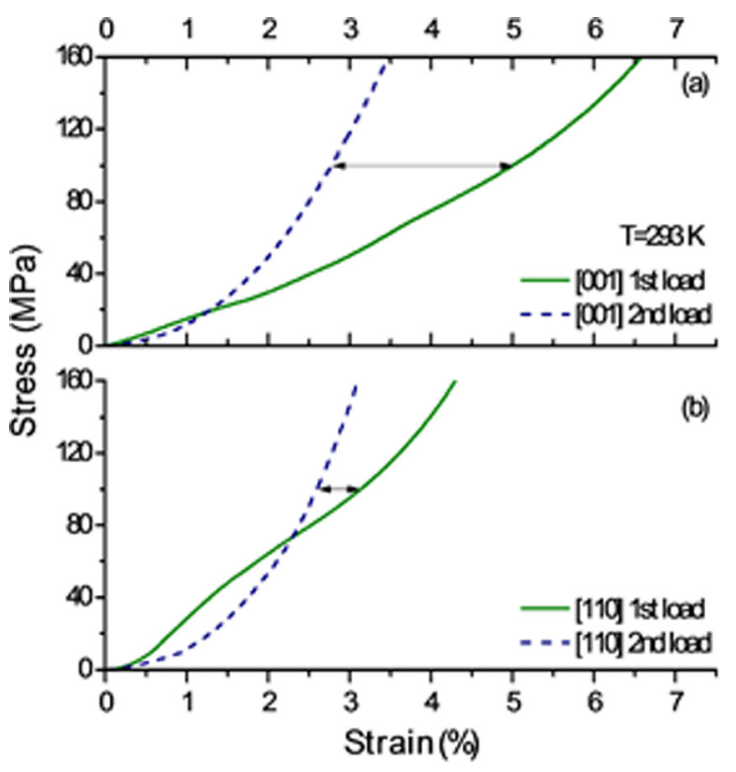

FIG. 5. Stress-strain curves of $\mathrm{Ni}_{50} \mathrm{Mn}_{32} \mathrm{In}_{16} \mathrm{Cr}_{2}$ applying compressive stress up to $160 \mathrm{MPa}$ in (a) [001] and (b) [110]. The second load is presented as the dashed line. 
elastocaloric effect during the unloading for the $\mathrm{Ni}_{50} \mathrm{Mn}_{32} \mathrm{In}_{16} \mathrm{Cr}_{2}$ alloy for [001] is as good as recent reports in $\mathrm{Ni}_{45.7} \mathrm{Mn}_{36.6} \mathrm{In}_{13.3} \mathrm{Co}_{5.1}{ }^{23}$ and $\mathrm{Ni}_{50} \mathrm{Mn}_{31.5} \operatorname{In}_{16} \mathrm{Cu}_{2.5}{ }^{32}$ and also higher than in other similar alloys previously reported. $22,31,33$ Nevertheless, this value is slightly lower than the one presented in $\mathrm{Ni}_{54} \mathrm{Fe}_{19} \mathrm{Ga}_{27}$. ${ }^{34}$ It is worth noticing that the reversible adiabatic temperature change in our $\mathrm{Ni}_{50} \mathrm{Mn}_{32} \mathrm{In}_{16} \mathrm{Cr}_{2}$ alloy due to $\Delta \sigma=75 \mathrm{MPa}$ is comparable with that presented in the $\mathrm{Ni}_{45.7} \mathrm{Mn}_{36.6} \mathrm{In}_{13.5} \mathrm{Co}_{4.2}$ alloy due to an $\Delta \mu_{0} \mathrm{H}=2 \mathrm{~T}$ external magnetic field. ${ }^{35}$

In summary, we measured the elastocaloric effect in textured polycrystalline $\mathrm{Ni}_{50} \mathrm{Mn}_{32} \mathrm{In}_{16} \mathrm{Cr}_{2}$ samples. We propose taking advantage of the characteristic texture induced through synthesis by arc melting to reach a high and reversible value of adiabatic temperature change. The unloading of $100 \mathrm{MPa}$ induces a reversible adiabatic temperature change $\Delta T_{\mathrm{ad}}{ }^{\text {me }}$ of -3.9 along the columnar growth direction [001], and it is remarkably larger than the $\Delta T_{\mathrm{ad}}{ }^{\text {me }}$ value of -2.0 and $-1.3 \mathrm{~K}$ displayed when the stress is applied along the [111] and [011] directions, respectively. In spite of the characteristic brittleness of the ferromagnetic shape memory alloys synthetized by arc melting, a $100 \mathrm{MPa}$ compressive stress was applied on $\mathrm{Ni}_{50} \mathrm{Mn}_{32} \mathrm{In}_{16} \mathrm{Cr}_{2}$ without inducing visible fracture in the sample. The strength of the elastocaloric effect in the direction [001] is comparable with the highest values reported up until now.

The authors would like to thank Beatriz Adriana RiveraEscoto for technical support and Laboratorio Nacional de Investigaciones en Nanociencias y Nanotecnología LINANIPICYT for the availability of their lab facilities. This work was supported by CONACYT (Mexico), Project Nos. CB-2010-01-157541 and SEP-CB-2015-01-257120, Asturias Government, Spain (FC-15-GRUPIN14-037 245), and MAT2014-56116-C4-3-4-R (MINECO, Spain).

${ }^{1}$ L. Mañosa, A. Planes, and M. Acet, J. Mater. Chem. A 1, 4925 (2013).

${ }^{2}$ X. Moya, S. Kar-Narayan, and N. D. Mathur, Nat. Mater. 13, 439 (2014).

${ }^{3}$ T. Krenke, E. Duman, M. Acet, E. F. Wassermann, X. Moya, L. Mañosa, A. Planes, E. Suard, and B. Ouladdiaf, Phys. Rev. B 75, 104414 (2007).

${ }^{4}$ A. Planes, L. Mañosa, X. Moya, T. Krenke, M. Acet, and E. F. Wassermann, J. Magn. Magn. Mater. 310, 2767 (2007).

${ }^{5}$ E. Stern-Taulats, P. O. Castillo-Villa, L. Mañosa, C. Frontera, S. Pramanick, S. Majumdar, and A. Planes, J. Appl. Phys. 115, 173907 (2014).

${ }^{6}$ W. Goetzler, R. Zogg, J. Young, and C. Johnson, Energy Savings Potential and RD\&D Opportunities for Non-Vapor-Compression HVAC Technologies, Prepared for U.S. Department of Energy (Navigant Consulting, Inc, 2014).

${ }^{7}$ B. Lu and J. Liu, Sci. Bull. 60(19), 1638 (2015).
${ }^{8}$ A. S. Starkov and I. A. Starkov, J. Exp. Theor. Phys. 119, 258 (2014).

${ }^{9}$ R. Millán-Solsona, E. Stern-Taulats, E. Vives, A. Planes, J. Sharma, A. K. Nayak, K. G. Suresh, and L. Mañosa, Appl. Phys. Lett. 105, 241901 (2014).

${ }^{10}$ J. P. Camarillo, C. O. Aguilar-Ortiz, H. Flores-Zúñiga, D. Ríos-Jara, D. E. Soto-Parra, E. Stern-Taulats, L. Mañosa, and A. Planes, Funct. Mater. Lett. 10, 1740007 (2017).

${ }^{11}$ S. Qian, Y. Geng, Y. Wang, J. Ling, Y. Hwang, R. Radermacher, I. Takeuchi, and J. Cui, Int. J. Refrig. 64, 1 (2016).

${ }^{12}$ H. Hou, E. Simsek, D. Stasak, N. Al Hasan, S. Qian, R. Ott, J. Cui, and I. Takeuchi, J. Phys. D: Appl. Phys. 50, 404001 (2017).

${ }^{13}$ J. Frenzel, E. P. George, A. Dlouhy, C. Somsen, M. F. Wagner, and G. Eggeler, Acta Mater. 58, 3444 (2010).

${ }^{14}$ Z. H. Liu, G. T. Li, Z. G. Wu, X. Q. Ma, Y. Liu, and G. H. Wu, J. Alloys Compd. 535, 120 (2012).

${ }^{15}$ R. Kainuma, Y. Imano, W. Ito, Y. Sutou, H. Morito, S. Okamoto, O. Kitakami, K. Oikawa, A. Fujita, T. Kanomata, and K. Ishida, Nature 439, 957 (2006).

${ }^{16}$ W. Ito, Y. Imano, R. Kainuma, Y. Sutou, K. Oikawa, and K. Ishida, Metall. Mater. Trans. A 38, 759 (2007).

${ }^{17}$ R. Kainuma, Y. Imano, W. Ito, H. Morito, Y. Sutou, K. Oikawa, A. Fujita, K. Ishida, S. Okamoto, O. Kitakami, and T. Kanomata, Appl. Phys. Lett. 88, 192513 (2006).

${ }^{18}$ L. Mañosa, D. González-Alonso, A. Planes, E. Bonnot, M. Barrio, J. L. Tamarit, S. Aksoy, and M. Acet, Nat. Mater. 9, 478 (2010).

${ }^{19}$ E. Stern-Taulats, A. Planes, P. Lloveras, M. Barrio, J. L. Tamarit, S. Pramanick, S. Majumdarc, S. Yüce, B. Emre, C. Frontera, and L. Mañosa, Acta Mater. 96, 324 (2015).

${ }^{20}$ E. Bonnot, R. Romero, L. Mañosa, E. Vives, and A. Planes, Phys. Rev. Lett. 100, 125901 (2008).

${ }^{21}$ F. Xiao, M. Jin, J. Liu, and X. Jin, Acta Mater. 96, 292 (2015).

${ }^{22}$ Y. J. Huang, Q. D. Hu, N. M. Bruno, J. H. Chen, I. Karaman, J. H. Ross, Jr., and J. G. Li, Scr. Mater. 105, 42 (2015).

${ }^{23}$ B. Lu, F. Xiao, A. Yan, and J. Liu, Appl. Phys. Lett. 105, 161905 (2014).

${ }^{24}$ F. Bachmann, R. Hielscher, and H. Schaeben, Solid State Phenom. 160, 63 (2010).

${ }^{25}$ P. O. Castillo-Villa, D. E. Soto-Parra, J. A. Matutes-Aquino, R. A. OchoaGamboa, A. Planes, L. Mañosa, D. González-Alonso, M. Stipcich, R. Romero, D. Ríos-Jara, and H. Flores-Zúñiga, Phys. Rev. B 83, 174109 (2011).

${ }^{26}$ J. Marcos, A. Planes, L. Mañosa, F. Casanova, X. Batlle, A. Labarta, and B. Martínez, Phys. Rev. B 66, 224413 (2002).

${ }^{27}$ J. L. Sánchez Llamazares, T. Sanchez, J. D. Santos, M. J. Pérez, M. L. Sanchez, B. Hernando, L. Escoda, J. J. Suñol, and R. Varga, Appl. Phys. Lett. 92, 012513 (2008).

${ }^{28}$ J. Tušek, K. Engelbrecht, L. Mañosa, E. Vives, and N. Pryds, Shape Mem. Superelasticity 2, 317 (2016).

${ }^{29}$ J. Cui, Y. Wu, J. Muehlbauer, Y. Hwang, R. Radermacher, S. Fackler, M. Wuttig, and I. Takeuchi, Appl. Phys. Lett. 101, 073904 (2012).

${ }^{30}$ J. Tušek, K. Engelbrecht, L. P. Mikkelsen, and N. Pryds, J. Appl. Phys. 117, 124901 (2015).

${ }^{31}$ D. Zhao, J. Liu, Y. Feng, W. Sun, and A. Yan, Appl. Phys. Lett. 110, 021906 (2017).

${ }^{32}$ D. Zhao, J. Liu, X. Chen, W. Sun, Y. Li, M. Zhang, Y. Shao, H. Zhang, and A. Yan, Acta Mater. 133, 217 (2017).

${ }^{33}$ B. Lu, P. Zhang, Y. Xu, W. Sun, and J. Liu, Mater. Lett. 148, 110 (2015).

${ }^{34}$ Y. Xu, B. Lu, W. Sun, A. Yan, and J. Liu, Appl. Phys. Lett. 106, 201903 (2015).

${ }^{35}$ T. Gottschall, K. P. Skokov, B. Frincu, and O. Gutfleisch, Appl. Phys. Lett. 106, 021901 (2015). 